\title{
In Vivo Assay of Folate Receptors in Nonfunctional Pituitary Adenomas with ${ }^{99 m}$ Tc-Folate SPECT/CT
}

\author{
James R. Galt ${ }^{1}$, Raghuveer K. Halkar ${ }^{1}$, Chheng-Orn Evans ${ }^{2}$, Naema A. Osman ${ }^{2}$, David LaBorde ${ }^{2}$, Timothy H. Fox ${ }^{3}$, \\ Bajat A. Faraj ${ }^{1}$, Kush Kumar ${ }^{1}$, Houping Wang ${ }^{2}$, and Nelson M. Oyesiku ${ }^{2}$ \\ ${ }^{1}$ Department of Radiology, Emory University, Atlanta, Georgia; ${ }^{2}$ Department of Neurosurgery, Emory University, Atlanta, Georgia; \\ and ${ }^{3}$ Department of Radiation Oncology, Emory University, Atlanta, Georgia
}

\begin{abstract}
The objective of this study was to evaluate the in vivo assay of folate receptors in nonfunctional pituitary adenomas using preoperative ${ }^{99 m T c-f o l a t e ~ S P E C T / C T ~ a n d ~ W e s t e r n ~ b l o t ~ a n a l y s i s ~(W B A) ~ o f ~}$ surgical specimens as the standard. Methods: Fifty-six patients (29 men, 27 women; age range, 29-82 y) with clinically nonfunctional pituitary adenomas on MRI underwent preoperative imaging using $666 \mathrm{MBq}(18 \mathrm{mCi})$ of $99 \mathrm{mTc}$-folate. SPECT/CT images and whole-body and lateral head planar images were acquired approximately $2 \mathrm{~h}$ after injection. Surgical resection took place within a week. WBA on a portion of the excised specimens assessed folate receptor expression in 49 patients. Attenuation-corrected $99 \mathrm{mTc}$ folate SPECT/CT images were assessed qualitatively and quantitatively (maximal adenoma counts to background), with WBA as a standard. Results: Integrated CT was useful for uptake localization and assisted region-of-interest placement. Qualitative interpretation of planar imaging yielded a sensitivity of $81 \%$ and specificity of $72 \%$. Qualitative SPECT/CT yielded a sensitivity of $94 \%$ and specificity of $61 \%$. Receiver-operating-characteristic curve analysis of quantitative uptake yielded a tumor-to-background cutoff ratio of 3.5 , with a sensitivity of $81 \%$ and specificity of $83 \%$. Scalp uptake yielded consistent results (over the brain, neck, and choroid plexus) for background when SPECT/CT misalignment artifacts were avoided. Detection of pituitary uptake on anterior-posterior and lateral images was hampered by facial uptake, which varied

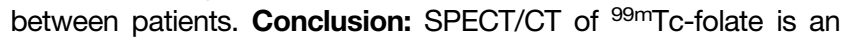
accurate method of assaying folate receptors in vivo and may provide a quantitative marker for identifying folate receptor-positive tumors. This method may also prove beneficial in selecting patients for folate-targeted therapy of clinically nonfunctional pituitary adenomas, for which there is currently no medical therapy.
\end{abstract}

Key Words: SPECT/CT; folate receptor; pituitary adenoma

J Nucl Med 2010; 51:1716-1723

DOI: 10.2967/jnumed.108.061689

\section{$\mathbf{P}$}

ituitary adenomas are frequently occurring intracranial tumors that can cause significant morbidity (1-3). Functional pituitary adenomas produce specific hormones and cause life-threatening diseases, infertility, and impotence.

Received May 5, 2009; revision accepted Aug. 13, 2010.

For correspondence or reprints contact: James R. Galt, Department of Radiology, Emory University Hospital, Atlanta, GA 30322.

E-mail: jgalt@emory.edu

COPYRIGHT @ 2010 by the Society of Nuclear Medicine, Inc.
Nonfunctional pituitary adenomas, the most common pituitary tumors, do not secrete hormones and cause damage through compression of regional structures. Unlike functional pituitary adenomas, there is no available effective medical therapy for nonfunctional adenomas. Though initial diagnosis of the adenoma may be delayed because of lack of symptoms, nonfunctional adenomas are easily detected by MRI and are enhanced with MRI contrast. Surgery to remove these adenomas is the treatment of choice but can be challenging because of their proximity to the carotid artery and optic nerve and their invasiveness. Some residual adenoma may remain after surgery, and patients are at risk of recurrence for several years after surgery (4).

Investigation of the molecular changes that contribute to the development of pituitary adenomas has shown that the folate receptor $\alpha(F R \alpha)$, a high-affinity folate transporter, is significantly overexpressed in clinically nonfunctional adenomas but not in functional adenomas (5). It was also found that FR $\alpha$ expression in nonfunctional pituitary adenomas was uniform throughout the adenoma and varies significantly between patients (5). Elevated levels of FR $\alpha$ promote folate acid uptake, alter signal transduction (6-9), and facilitate growth of nonfunctional pituitary adenomas in vitro $(10,11)$. The ability to assay folate receptors noninvasively may be valuable as a prognostic measure of tumor aggressiveness and provide a tool for the selection of nonfunctional pituitary adenomas that may respond to folate-targeted therapy. Without such a diagnostic test, obtaining this information would require immunohistologic or molecular examination of specimens obtained at surgery.

Radiopharmaceuticals have been investigated as scintigraphic imaging agents for the in vivo assay of folate receptors in clinical studies. ${ }^{111}$ In-diethylenetriaminepentaacetic acid-folate scintigraphy has been investigated as a tool for differentiating between malignant and benign ovarian masses (12). Scintigraphy with ${ }^{99 \mathrm{~m} T c-E C 20}$ (FolateScan; Endocyte, Inc.) has been investigated in various tumors that are folate receptor-positive $(\mathrm{FR}+)$. Preclinical studies in a rodent model indicated that ${ }^{99 \mathrm{~m} T c-E C 20}$ uptake was specific and proportional to folate receptor expression levels in tumor cells, linear with tumor size, and independent of tumor location (13). In a clinical study, tumors with ${ }^{99 \mathrm{~m} T c-E C 20}$ uptake 
were identified in $68 \%$ of the 154 patients studied with proven or suspected cancer (14).

The objective of this study was to evaluate the in vivo assay of folate receptors in nonfunctional pituitary adenomas using preoperative ${ }^{99 \mathrm{~m}} \mathrm{Tc}-\mathrm{EC} 20$ planar scintigraphy and SPECT/CT. Western blot analysis (WBA) using a polyclonal antihuman antibody of surgical specimens was used as the reference for comparison. The sensitivity and specificity of each diagnostic modality has been determined on the basis of a qualitative interpretation of results as compared with those from Western blot. Quantitative analysis based on tumor-toscalp count ratios extracted from the SPECT/CT scans was also examined, and a receiver-operating-characteristic (ROC) curve was created to examine the optimal cutoff ratio.

\section{MATERIALS AND METHODS}

\section{Patient Population}

Fifty-six patients (age range, 29-82 y; mean age, 55 y; 29 men, 27 women) with clinically nonfunctional pituitary adenomas were evaluated. Each patient presented with a visual deficit and a hormone profile consistent with clinically nonfunctional pituitary adenoma, and the presence of tumor was confirmed by MRI. After a medical evaluation and pregnancy test (if applicable), the patients were scheduled for surgery to remove the tumor, with ${ }^{99 m}$ Tc-EC20 scintigraphy before surgery. After surgery, WBA was performed on a portion of the excised surgical specimens of 49 patients to detect folate receptor expression (WBA could not be obtained for 7 patients). The first 6 patients were also included in another, multisite study of various tumor types (14). The study protocol was approved by the Emory University Institutional Review Board, and all patients gave written informed consent before participation.

\section{Radiopharmaceutical Preparation and Injection}

Folate-labeled ${ }^{99 \mathrm{~m}} \mathrm{Tc}-\mathrm{EC} 20$ for injection was packaged as a sterile lyophilized powder in a single-reagent vial containing the components EC20 $(100 \mu \mathrm{g})$, sodium $\alpha$-D-glucoheptonate dihydrate
$(80 \mu \mathrm{g})$, and tin (II) chloride dihydrate $(80 \mu \mathrm{g}) .{ }^{99 \mathrm{~m} T \mathrm{~T}-\mathrm{EC} 20}$ was prepared in the hospital radiopharmacy by adding up to $1,850 \mathrm{MBq}$ of ${ }^{99 \mathrm{~m}} \mathrm{Tc}$-sodium pertechnetate into the vial and heating the vial in a boiling water bath for approximately $18 \mathrm{~min}$. The radiochemical purity of ${ }^{99 \mathrm{~m} T c-E C 20}$ was determined by thin-layer chromatography at the time of preparation and was required to be $90 \%$ for administration (13-15).

Patients were asked to discontinue taking folic acid supplements $2 \mathrm{~d}$ before the imaging study. The patients underwent 2 injections via a free-flowing intravenous catheter in an upper extremity vein. The first injection contained $0.5-1 \mathrm{mg}$ of folic acid. The second contained $1-2 \mathrm{~mL}$ of folate $(0.1 \mathrm{mg})$ labeled with $666 \mathrm{MBq}$ of ${ }^{99 \mathrm{~m}} \mathrm{Tc}$ ( $\left.{ }^{99 \mathrm{~m}} \mathrm{Tc}-\mathrm{EC} 20\right)$. The purpose of the first injection was to saturate the folate receptors in normal tissues, thus reducing the extratumor uptake of ${ }^{99 \mathrm{~m} T c-E C 20}$. The time delay between the first and second injections was 3 min for the first 7 patients and $30 \mathrm{~min}$ for the remainder of patients. These changes in protocol were suggested by the manufacturer, but this study does not provide sufficient data to evaluate the optimal time between injections or the dosage of nonlabeled folic acid.

\section{Imaging}

Imaging began approximately $2.5 \mathrm{~h}$ after injection, with each patient undergoing whole-body imaging and SPECT/CT (average time for SPECT/CT, $2.8 \mathrm{~h}$ after injection). Lateral static images of the head were obtained for all but the first 6 patients. Twenty-three patients underwent a second SPECT/CT study (average time, $4.7 \mathrm{~h}$ after injection) before completion of their evaluation to determine whether changes in the distribution of ${ }^{99 \mathrm{~m}}$ Tc-EC20 would affect uptake ratios or study interpretation between early and late scans. All images were acquired on a dual-detector, large-field-of-view SPECT/CT system equipped with low-energy high-resolution parallel-hole collimation and using a 140-keV, $20 \%$ energy window (VG/Hawkeye; GE Healthcare). Images were reconstructed, displayed, and evaluated on a clinical nuclear medicine workstation (Xeleris 2.0; GE Healthcare).

Whole-body images were acquired in a $1,024 \times 256$ matrix ( $2.4 \mathrm{~mm} / \mathrm{pixel}$ ) from head to mid thigh using continuous motion at $15.5 \mathrm{~cm} / \mathrm{min}$ (giving an effective exposure time of $131 \mathrm{~s}$ ).
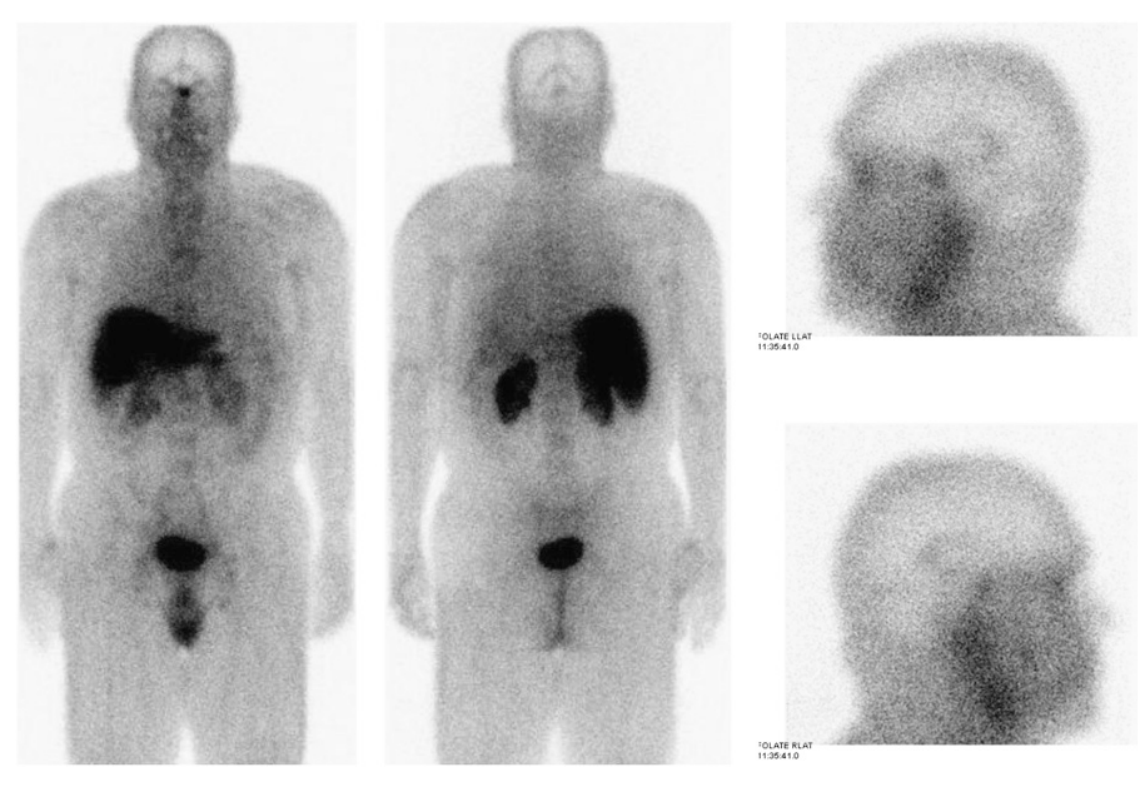

FIGURE 1. Whole-body and lateral head static images of patient with FR+ nonfunctional pituitary adenoma. Pituitary adenoma, which had estimated volume of $2.7 \mathrm{~mL}$, is clearly visible in most images. Uptake is also seen in liver, kidneys, bladder, and choroid plexus. LLAT = left lateral; RLAT $=$ right lateral. 
Lateral head static images were acquired in a $256 \times 256$ matrix, with a $2.0 \mathrm{zoom}(1.1 \mathrm{~mm} / \mathrm{pixel})$ for $5 \mathrm{~min}$. Planar images of a $\mathrm{FR}+$ patient are shown in Figure 1.

For SPECT/CT, CT images were acquired first using a slowrotation low-radiation dose that took 5-7 min (1-cm-thick slices, $256 \times 256$ matrix, $1.7 \mathrm{~mm} /$ pixel), from the top of the head to the patient's shoulders. SPECT images were acquired immediately on completion of the CT, with a 1.28 zoom $(128 \times 128$ matrix, $3.4 \mathrm{~mm} /$ pixel) using a continuous orbit with 120 projections (15 min total acquisition time). SPECT images were reconstructed with and without attenuation correction using ordered-subset expectation maximization (6 iterations, 10 subsets). A 3-dimensional Butterworth filter (critical frequency of $0.61 / \mathrm{cm}$, power factor of 10.0 ) was applied after reconstruction. SPECT/CT images of a FR + and folate receptor-negative $(\mathrm{FR}-)$ patients are shown in Figure 2.

\section{Surgical Resection and Tumor Evaluation}

Transsphenoidal surgical resection took place within a week in all but 2 of the patients, who had delays of 2 and 6 wk. After surgery, WBA was performed on a portion of the excised surgical specimens of 49 patients to detect folate receptor expression (WBA could not be obtained for 7 patients). The WBA was performed as follows. Thirty milligrams of the excised tissue (each tumor is excised in several pieces weighing 100-1,000 mg) were homogenized and the protein concentration measured. Equal portions of the homogenized samples $(20 \mu \mathrm{g})$ were loaded onto a $15 \%$ acrylamide-sodium dodecylsulfate gel, and proteins were resolved by electrophoresis. The proteins were then transferred into nitrocellulose, and FR $\alpha$ was detected using a polyclonal antihuman FR $\alpha$ antibody. The antibody was produced by rabbits immunized with a recombinant $\mathrm{FR} \alpha$-glutathione S-transferase fusion protein (16). The FR $\alpha$ protein was visualized using a horseradish peroxidase-conjugated antirabbit $\operatorname{IgG}$ as the secondary antibody (catalog no. A-4914; Sigma/Aldrich) and the enhanced chemiluminescence WBA system (catalog no. RPN2132; GE Healthcare) on Biomax ML film (Kodak). The films were scanned with a densitometer, and the absorbance of the FR $\alpha$ protein bands was measured using UN-SCAN-IT Gel Analysis Software (Silk Scientific, Inc.). The software subtracts the background for each film and normalizes it to a standard with known high folate receptor expression (included with each measurement). The Western blot scored the presence of FR $\alpha$ in the tumors as 1 (absent: $0.1 \%-$ $25 \%$ of the density of the standard), 2 (moderate: $26 \%-70 \%$ ), or 3 (marked: $71 \%-100 \%$ ). These cutoff percentages were derived from our experience with Western blotting. WBA films of the patients whose images were shown in Figure 2 are shown in Figure 3. The absorbance value of each tumor sample indicated the $\mathrm{FR} \alpha$ protein expression per $20 \mu \mathrm{g}$ of total protein.

\section{Image Analysis}

Planar images (whole-body and lateral head static) were read by an experienced nuclear medicine physician who documented areas of uptake, with particular note of the pituitary area. SPECT/ CT images were read using an integrated display that showed the attenuation-corrected and noncorrected SPECT, CT, and fused images. The same grading scale (absent, moderate, and marked) as was used for the Western blot was used to note tumor uptake. For sensitivity and specificity analysis, the absent category was considered to be a negative result, whereas moderate and marked assessments were considered a positive result representing the presence of $\operatorname{FR} \alpha$ expression.

Quantitative analysis was applied as a count ratio of tumor-tobackground counts in the attenuation-corrected SPECT images. Tumor counts were measured by locating the SPECT slice with the greatest tumor uptake and extracting maximal counts from a small region of interest (ROI) drawn over the tumor. Where tumor
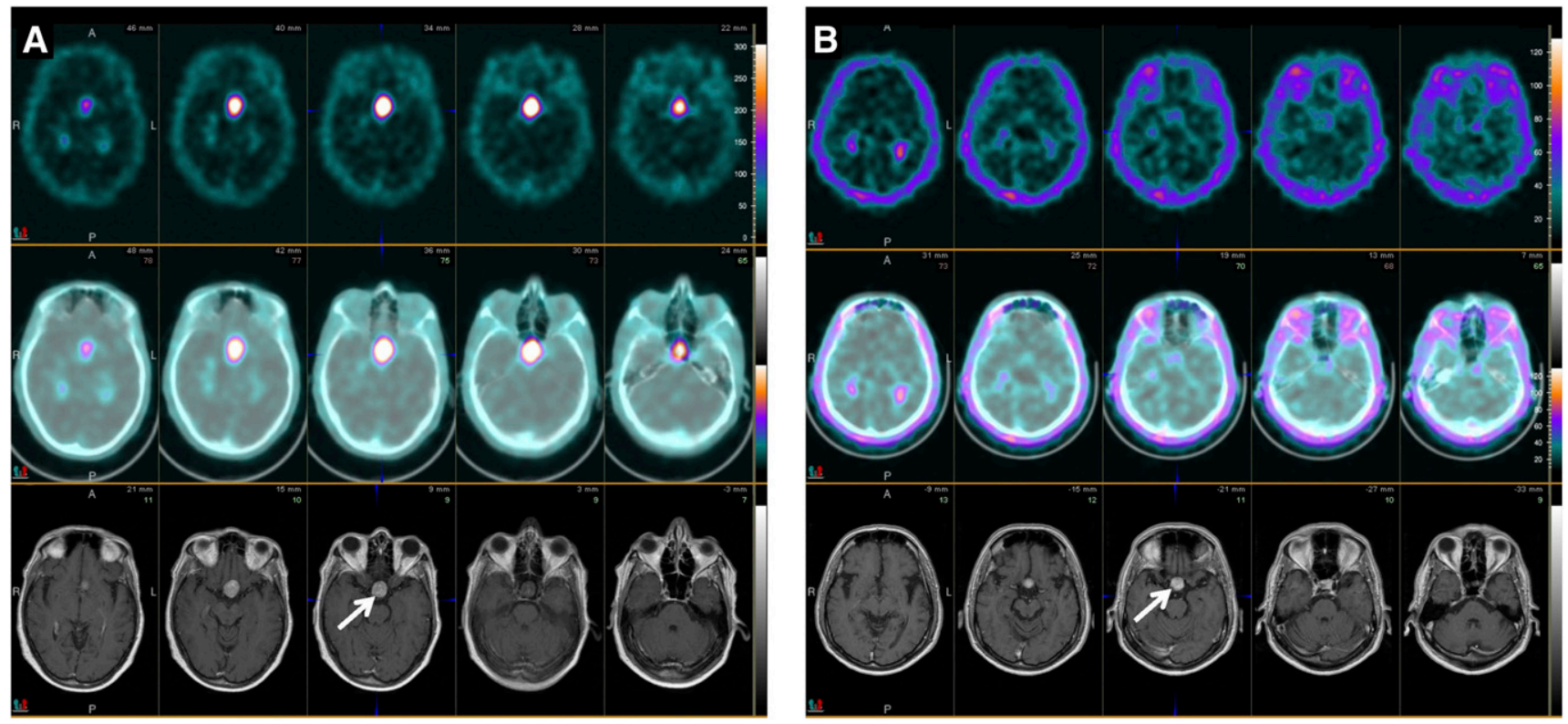

FIGURE 2. SPECT/CT images and registered contrast-enhanced MR images of 2 patients with nonfunctional pituitary adenomas: FR+ tumor (A) with estimated volume of $6.0 \mathrm{~mL}$ and $\mathrm{FR}$ - tumor (B) with estimated volume of $3.9 \mathrm{~mL}$. Imaging times were 2.9 and $2.5 \mathrm{~h}$, respectively, after injection. From top to bottom, panels show SPECT, SPECT/CT fusion with low-dose integrated CT, and contrastenhanced MR images. Tumor location is indicated with arrow on MR images. 

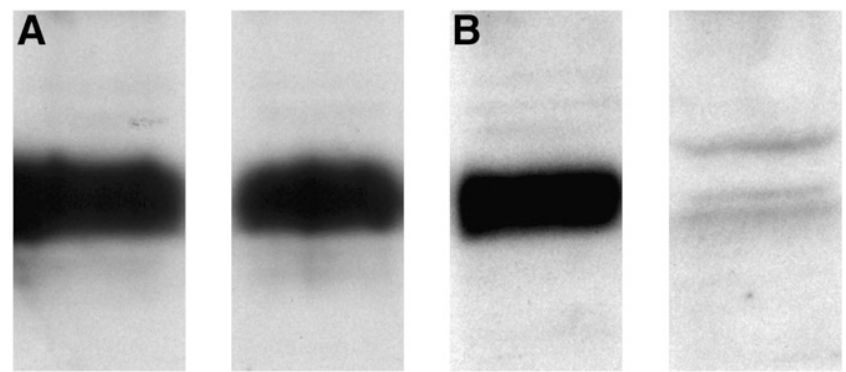

FIGURE 3. Western blot correlation for the 2 patients in Figure 2: FR + tumor (A) and FR - tumor (B). Western blot of markedly positive standard is shown on left and that of sample taken from excised tumor is on right.

uptake could not be noted, the CT image was used to locate the tumor or to estimate the tumor location, and an ROI was placed there. The CT image on this system, however, suffered from slices that were too thick at $1 \mathrm{~cm}$ to allow the CT image to be used to outline the tumor completely. Scalp uptake was evaluated by extracting maximal counts from an ROI drawn over a lateral or inferior area of the scalp (chosen to avoid attenuation-correction artifacts caused by misalignment of the SPECT and CT images). The choroid plexus, cortex, and neck were investigated but proved to be too variable (choroid plexus and neck) or too low in counts (cortex) for use as background.

\section{RESULTS}

\section{Planar Images}

Although many tumors were clearly visible in the wholebody and lateral head static images (Fig. 1, for example), the ${ }^{99 \mathrm{~m}} \mathrm{Tc}-\mathrm{EC} 20$ uptake was often obscured by extratumor uptake, primarily from the sinus area. This made determination of tumor uptake difficult in several patients. Other areas of uptake included the liver, kidneys, and choroid plexus in all patients. Incidental areas of uptake in some patients included the bone marrow and inguinal lymph nodes. Extratumor uptake prevented accurate measurement of counts in the planar images. Comparison of the physician's interpretation of the tumor uptake from the planar images with the WBA is shown in Tables 1 and 2. The qualitative assessment of the static whole-body and lateral

TABLE 1

Qualitative Interpretation of Planar Scintigraphy

\begin{tabular}{llcr}
\hline & \multicolumn{3}{c}{ Western blot FR $\alpha$ level } \\
\cline { 2 - 4 } Scan uptake & 3 & 2 & 1 \\
\hline 3 & 9 & 7 & 1 \\
2 & 3 & 6 & 4 \\
1 & 1 & 5 & 13
\end{tabular}

Physician interpretation of tumor uptake of ${ }^{99 m T C-E C 20 ~ f r o m ~}$ planar images (whole body and lateral head static), compared with WBA of FR $\alpha$ in tumor. Both were graded on 3-point scale: 1, absent; 2, moderate; or 3, marked.
TABLE 2

Planar Scintigraphy Sensitivity and Specificity

\begin{tabular}{lrr}
\hline \multirow{2}{*}{ Scan uptake } & \multicolumn{2}{c}{ Western blot FR $\alpha$} \\
\cline { 2 - 3 } & + & - \\
\hline+ & 25 & 5 \\
- & 6 & 13
\end{tabular}

Physician interpretation of tumor uptake of ${ }^{99 m T c-E C 20 ~ f r o m ~}$ planar images (whole body and lateral head static), compared with WBA of FR $\alpha$ in tumor on positive-negative scale. Interpretation yielded sensitivity of $81 \%$ and specificity of $72 \%$.

head images yielded a sensitivity of $81 \%$ and a specificity of $72 \%$ using the WBA as a standard.

\section{SPECT Images}

Qualitative analysis of the SPECT/CT images by the experienced nuclear medicine physician noted that the CT image helped with localization of the tumor, particularly in patients with little tumor uptake. Attenuation correction made the tumor much more readily visible, as might be expected because it is an interior structure, particularly important in patients with marked facial or sinus uptake. Comparison of the physician's interpretation of the tumor uptake from the SPECT/CT image with the WBA is shown in Tables 3 and 4. The qualitative assessment of the SPECT/ CT images yielded a sensitivity of $94 \%$ and a specificity of $61 \%$ using the WBA as a standard.

Comparison of the tumor-to-scalp (tumor-to-background) count ratios with the qualitative assessment (Fig. 4) showed little overlap of the count ratios of patients noted as having a marked or moderate tumor uptake. There was more overlap of count ratios between the patients noted with absent ( 1 on the $y$-axis) tumor uptake. Comparison of the same ratios to the Western blot results showed that the count ratios were not as delineated by category as they were in the qualitative assessment (Fig. 5). This result is to be expected because the qualitative assessment did not agree with the WBA in all cases (Tables 1 and 3).

Early and late SPECT/CT images (23 patients) were scored exactly the same by the reviewer, with 2 exceptions.

TABLE 3

Qualitative Interpretation of SPECT/CT

\begin{tabular}{lrrr}
\hline & \multicolumn{3}{c}{ Western blot FR $\alpha$ level } \\
\cline { 2 - 4 } Scan uptake & 3 & 2 & 1 \\
\hline 3 & 12 & 13 & 4 \\
2 & 1 & 3 & 3 \\
1 & 0 & 2 & 11
\end{tabular}

Physician interpretation of tumor uptake of ${ }^{99 m T C-E C 20, ~ c o m-~}$ pared with WBA of FR $\alpha$ in tumor. Both were graded on 3-point scale: 1 , absent; 2 , moderate; or 3 , marked. 
TABLE 4

SPECT/CT Sensitivity and Specificity

\begin{tabular}{lrr}
\hline & \multicolumn{3}{c}{ Western blot FR $\alpha$} \\
\cline { 2 - 3 } Scan uptake & + & - \\
\hline+ & 29 & 7 \\
- & 2 & 11
\end{tabular}

Physician interpretation of tumor uptake of ${ }^{99 m T C-E C 20, ~ c o m-~}$ pared with WBA of FR $\alpha$ in tumor on positive-negative scale. This interpretation yielded sensitivity of $94 \%$ and specificity of $61 \%$.

Both exceptions were for patients whose images were scored as "moderate uptake" on the early but changed to "absent uptake" on the late images. Comparison of tumorto-scalp ratios from the early and late images showed that tumor-to-background tended to decrease slightly over time, with an average decrease in the ratio of $10 \%$ (SD of $17 \%$ ) in 15 (of the 23) patients that the reviewer scored with moderate or marked tumor uptake.

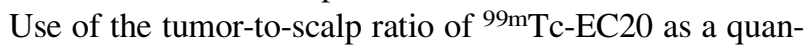
titative marker of the presence of folate receptors was investigated with ROC curve analysis, varying the tumor-to-scalp count ratio threshold for a positive result and subsequently calculating the corresponding sensitivity and specificity. The ROC curve is shown in Figure 6. A tumor-to-scalp cutoff ratio of 3.5 resulted in a sensitivity of $81 \%$ and specificity of $83 \%$ (Table 5).

\section{DISCUSSION}

The in vivo diagnosis of tumor receptor expression allows selection of tumors that may be treatable by targeted therapy, such as a folate drug conjugate or folate-based radionuclide therapy (17-20). Normal tissues, lacking in folate receptors, could be spared toxicity associated with nontargeted drug delivery. Folate-based imaging agents, including radiopharmaceuticals, may provide novel diagnostic testing by locating and assessing the receptor density of FR + tumors (21-23). Identification of tumors by imaging before surgery could be clinically significant should the
$\mathrm{FR}+$ lesions have a different natural history than the FRlesions or should effective medical therapy become available for FR + lesions (17-20).

Several labeled folate conjugates have been investigated for scintigraphic imaging; ${ }^{67} \mathrm{Ga}(24)$ and ${ }^{111}$ In-diethylenetriaminepentaacetic acid $(12,25,26)$ have been used but are costly and have long half-lives. ${ }^{99 \mathrm{~m}} \mathrm{Tc}$, with its 6 -h half-life and optimal $\gamma$-energy, is well suited for delivering the counting rates desired for same-day SPECT. Different chelators have been used to label ${ }^{99 \mathrm{~m}} \mathrm{Tc}$ with folate $(15,27-31)$. ${ }^{99 \mathrm{~m}}$ Tc-EC20 is the only ${ }^{99 \mathrm{~m}}$ Tc-based agent that has been used in a clinical study to date (14). This is a second clinical report with ${ }^{99 \mathrm{~m}}$ Tc-EC20 and the first in which it has been exclusively used to evaluate nonfunctional pituitary adenomas-benign brain tumors.

The purpose of receptor imaging in the management of pituitary tumors is not to localize or diagnose them (both investigations can be better performed with other imaging tools) but to identify the tumors that express the receptorssuch that targeted therapy can be applied to that subsetallowing personalized medicine that decreases toxicity and increases efficacy. Hence, receptor imaging is less important in tumors that always express receptors.

Whereas a previous clinical report with $99 \mathrm{~m}$ Tc-EC20 noted uptake in the choroid plexus in only 4 of 155 patients (14), uptake was noted in varying degrees in the SPECT/CT images of all the patients in this study. The apparent discrepancy is probably due to the fact that in the previous study (14) SPECT or lateral images of the head were obtained for only a few of the patients (the study dealt with different tumor types and SPECT was targeted at the known or suspected tumor). As with the pituitary adenomas, the choroid plexus was more easily visualized on the attenuation-corrected SPECT images than on the planar images. The finding of ${ }^{99 \mathrm{~m}}$ Tc-EC20 in the choroid plexus is in agreement with a preclinical study of $99 \mathrm{~m}$ Tc-His-folate, which also reported the presence of $99 \mathrm{~m}$ Tc-EC20 in the choroid plexus (32). In addition, the choroid plexus is known to express folate receptors (33). The uptake in the choroid plexus is probably not due to a small amount of free ${ }^{99 \mathrm{~m}}$ Tc-pertechnetate, as was speculated in an earlier study

FIGURE 4. Qualitative assessment of tumor uptake of $99 \mathrm{mTc}$-EC20 (as scored by physician on 3-point scale), compared with tumor-to-scalp count ratio. Little overlap of in count ratios is seen in patients with uptake that was noted as moderate (2) and marked (3), but the delineation of the absent (1) and moderate groups is not as striking.

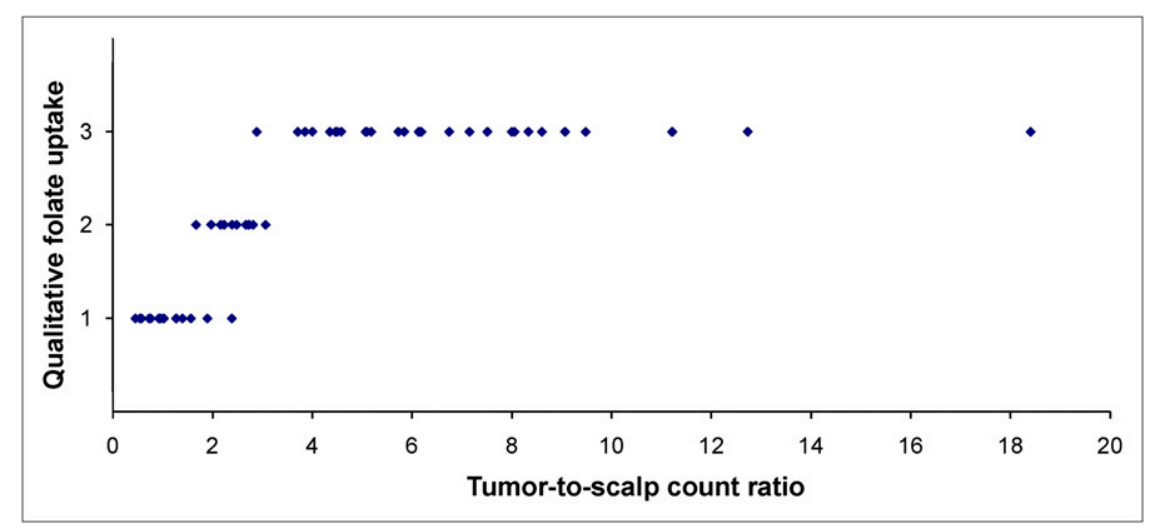




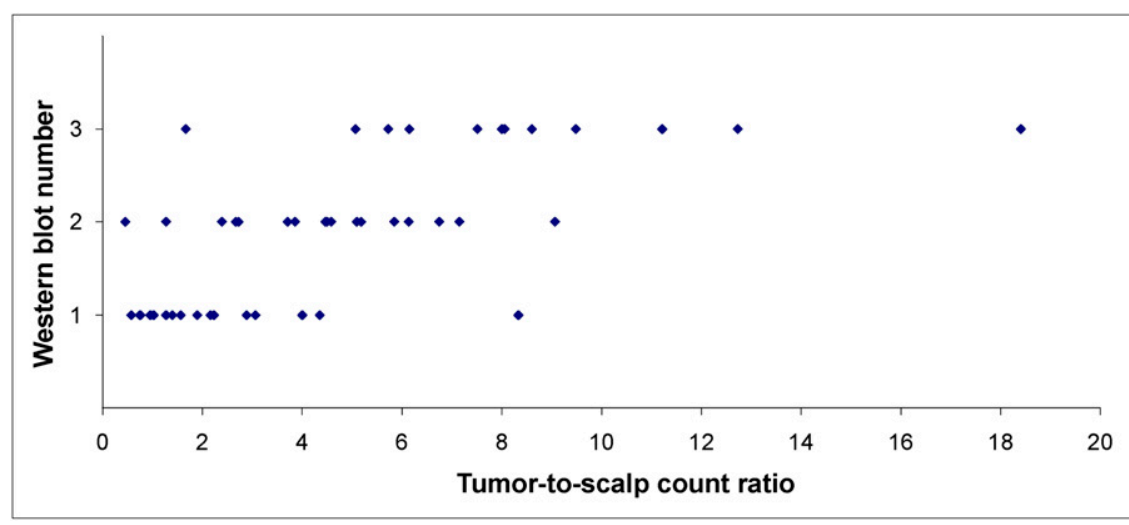

FIGURE 5. Western blot versus quantitative assessment of tumor uptake. FR $\alpha$ assessment by WBA is compared with tumor-to-scalp ratio. Count ratios are not as well delineated by category as they were in qualitative assessment.
(14), because uptake was not noted in the stomach or thyroid (as would be expected with free ${ }^{99 \mathrm{~m}} \mathrm{Tc}$-pertechnetate).

Planar scintigraphy, evaluated by an experienced physician, yielded a sensitivity of $81 \%$ and a specificity of $72 \%$ and was hampered by the presence of facial and sinus uptake in some patients, lowering the confidence in the interpretation. The addition of SPECT/CT dramatically raised the sensitivity (94\%) of a qualitative interpretation but also lowered specificity to $61 \%$. Quantitative evaluation of SPECT/CT tumor-to-scalp count ratios after selecting a tumor-to-scalp cutoff ratio of 3.5 based on ROC curve analysis substantially improved the specificity of SPECT/CT to $83 \%$, with a sensitivity of $81 \%$.

Although the gain in quantitative evaluation of SPECT/ CT was modest, it is possible that it would be useful in planning for treatment by giving a more accurate assessment of the receptor density. The work described here was done on a first-generation SPECT/CT scanner. Use of a

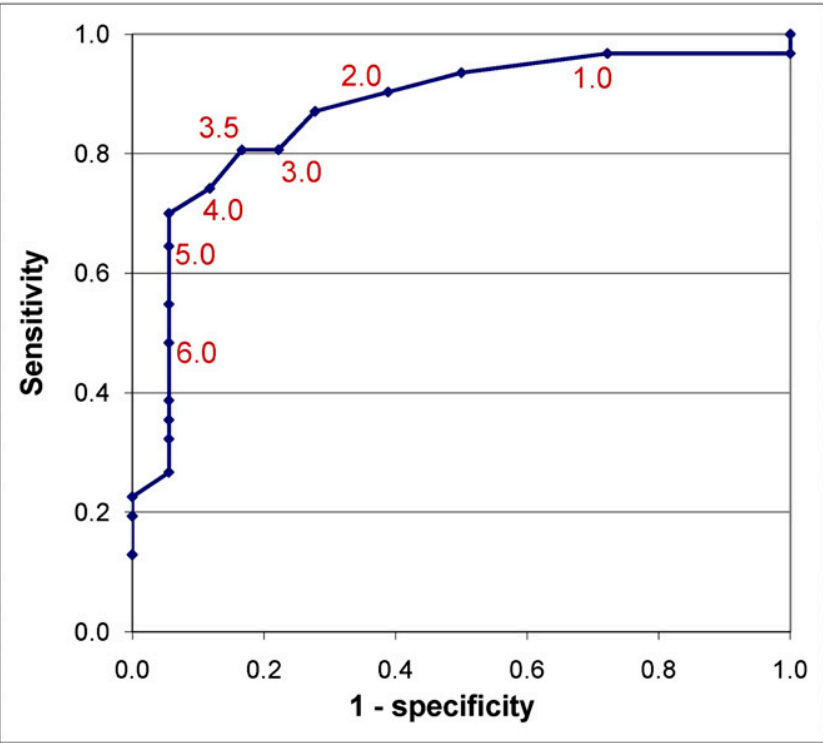

FIGURE 6. Tumor-to-scalp count ratio ROC curve. ROC curve was produced by varying the tumor-to-scalp count ratio as a threshold for determining whether tumor was positive for $F R \alpha$. Ratios are given in red next to corresponding point on curve. system with higher quality CT might improve the accuracy of the quantitation by making the ROI placement and selection of background areas less subjective. Correlation of the SPECT images with an MR image designed to complement the SPECT study would likely improve the quantitation by more accurately defining the tumor site.

An important factor that limits the accuracy of this study is that the SPECT images of the tumors are subject to partial-volume effects and, therefore, larger tumors may appear brighter in the images, simply because of their size (34). Compensation for partial-volume effects will likely require anatomic images that clearly delineate the tumor (35-38). Volumetric MRI with contrast may prove to be ideal for this, but unfortunately, all of the MR images cited in this work were obtained before the patient entered the study. Many of the scans were acquired at other institutions and were not available for a detailed review. To investigate the bias of the results in favor of higher counts in larger tumors due to partial-volume effect, MR images of a subset of the patients $(n=17)$ were used to estimate the size of the tumor by outlining the tumor in 3 dimensions (MIMVista Contouring; MIMVista Corp.). There was no correlation between the size of the tumor and any of the uptake measurements.

A delayed SPECT/CT acquisition, approximately $2 \mathrm{~h}$ after the initial, or early, acquisition, did not result in different qualitative diagnostic results. The late scans, as compared

TABLE 5

Quantitative SPECT/CT Sensitivity and Specificity

\begin{tabular}{lrr}
\hline & \multicolumn{2}{c}{ Western blot FR $\alpha$} \\
\cline { 2 - 3 } Quantitative assessment & + & - \\
\hline+ & 25 & 3 \\
- & 6 & 15
\end{tabular}

Tumor-to-scalp ${ }^{99 \mathrm{mTC}} \mathrm{TCC} 20$ count ratio threshold of 3.5 was used for presence of folate receptors, and sensitivity and specificity of results were calculated, compared with WBA of FR $\alpha$ in tumor on positive-negative scale. These calculations yielded a sensitivity of $81 \%$ and specificity of $83 \%$. 
with the early SPECT/CT images, proved to have slightly decreased tumor-to-scalp count ratios. The administration of cold folate before administration of ${ }^{99 \mathrm{~m}} \mathrm{Tc}-\mathrm{EC} 20$ in this work followed the manufacturer's recommendations. The effects of this administration have been documented in preclinical studies with other folate-based radiopharmaceuticals $(24,26)$, but a study designed to test the hypothesis behind giving the cold folate (that it will reduce the uptake in normal tissue, increasing tumor-to-soft-tissue contrast) for ${ }^{99 \mathrm{~m} T \mathrm{Tc}-\mathrm{EC} 20}$ would be beneficial.

Understanding the molecular basis of disease processes is essential to increase the efficacy and decrease the side effects of therapy through customization for individual patients. At present, the standard for assessing tumors is the histologic evaluation of excised tumor tissue. Histologic sampling, however, suffers when the sample contains material other than active tumor cells. This sampling bias could cause a reduction in the correlation between WBA and imaging. Another factor that may decrease the correlation is that ${ }^{99 \mathrm{~m}} \mathrm{Tc}-\mathrm{EC} 20$ will bind to both $\mathrm{FR} \alpha$ and FR $\beta$ receptors (39), whereas WBA detects only FR $\alpha$. This will also cause a decrease in the correlation by reducing the specificity calculated for the scan results in this study (without affecting the sensitivity). Because FR $\alpha$ and FR $\beta$ are both active in folate transport, an in vivo assay with ${ }^{99 \mathrm{~m} T c-E C 20}$ scintigraphy may be better than immunohistochemistry $(14,40)$ or even WBA for assessing real-time functioning activity of tissue-related folate receptors.

\section{CONCLUSION}

Molecular imaging, specifically 3-dimensional molecular imaging, has the bright prospect of assessing tumors in vivo. To our knowledge, this is the first study focusing on the use of ${ }^{99 \mathrm{~m} T c}$-labeled folates for imaging nonfunctional pituitary adenomas. Planar imaging of ${ }^{99 \mathrm{~m}} \mathrm{Tc}$-folate had good sensitivity and specificity ( $81 \%$ and $72 \%$, respectively), with a positive predictive value of $83 \%$. The addition of SPECT/CT improved the sensitivity (94\%), at some loss of specificity $(61 \%)$, by qualitative assessment. SPECT/CT improved the clinician's confidence in the location of any uptake noted and, consequently, the confidence of diagnoses. Quantitative analysis of the SPECT/CT image showed similar sensitivity to planar imaging (81\%) but higher specificity (83\%). Though the gain was modest, the higher specificity given by quantitative analysis of SPECT/CT images may prove useful when a diagnostic scan is used as a gateway to folate-based therapy by preventing the use of the therapy when it would not be beneficial. Improved quantitation through the use of a higherquality CT scan or by the use of image fusion with MRI may further improve the utility of quantitation.

The data demonstrate that ${ }^{99 \mathrm{~m} T c-E C 20}$ can successfully target FR + pituitary adenomas and support the possibility that folate receptor imaging might be useful in selecting patients who would benefit from folate receptor-targeted therapy. SPECT allowed for definite separation of pituitary uptake from facial or glandular uptake that sometimes overlies the tumor on planar scintigrams. Integrated CT was valuable for tumor localization, and corrections based on the CT may prove valuable for quantification of the SPECT tracer uptake, and, in turn, for therapy planning and dosimetry calculations.

\section{ACKNOWLEDGMENT}

This work was funded in part by the National Institutes of Health grant Molecular Targeting and Imaging of Pituitary Adenomas (NIH NS051439-03). The radiopharmaceutical ( ${ }^{99 \mathrm{~m}} \mathrm{Tc}$-folate [EC20; FolateScan]) was provided by Endocyte, Inc.

\section{REFERENCES}

1. Greenman Y, Melmed S. Diagnosis and management of nonfunctioning pituitary tumors. Annu Rev Med. 1996;47:95-106.

2. Ezzat S, Asa SL, Couldwell WT, et al. The prevalence of pituitary adenomas: a systematic review. Cancer. 2004;101:613-619.

3. Daly AF, Rixhon M, Adam C, Dempegioti A, Tichomirowa MA, Beckers A. High prevalence of pituitary adenomas: a cross-sectional study in the province of Liege, Belgium. J Clin Endocrinol Metab. 2006;91:4769-4775.

4. Losa M, Mortini P, Barzaghi R, et al. Early results of surgery in patients with nonfunctioning pituitary adenoma and analysis of the risk of tumor recurrence. J Neurosurg. 2008;108:525-532.

5. Evans CO, Reddy P, Brat DJ, et al. Differential expression of folate receptor in pituitary adenomas. Cancer Res. 2003;63:4218-4224.

6. Evans CO, Young AN, Brown MR, et al. Novel patterns of gene expression in pituitary adenomas identified by complementary deoxyribonucleic acid microarrays and quantitative reverse transcription-polymerase chain reaction. J Clin Endocrinol Metab. 2001;86:3097-3107.

7. Antony AC. The biological chemistry of folate receptors. Blood. 1992;79:2807-2820.

8. Ross JF, Chaudhuri PK, Ratnam M. Differential regulation of folate receptor isoforms in normal and malignant tissues in vivo and in established cell lines: physiologic and clinical implications. Cancer. 1994;73:2432-2443.

9. Moreno CS, Evans CO, Zhan X, Okor M, Desiderio DM, Oyesiku NM. Novel molecular signaling and classification of human clinically nonfunctioning pituitary adenomas identified by gene expression profiling and proteomic analyses. Cancer Res. 2005;65:10214-10222.

10. Evans CO, Yao C, Laborde D, Oyesiku NM. Folate receptor expression in pituitary adenomas cellular and molecular analysis. Vitam Horm. 2008;79:235-266.

11. Yao C, Evans CO, Stevens VL, Owens TR, Oyesiku NM. Folate receptor alpha regulates cell proliferation in mouse gonadotroph alphaT3-1 cells. Exp Cell Res. 2009;315:3125-3132.

12. Siegel BA, Dehdashti F, Mutch DG, et al. Evaluation of ${ }^{111}$ In-DTPA-folate as a receptor-targeted diagnostic agent for ovarian cancer: initial clinical results. J Nucl Med. 2003;44:700-707.

13. Reddy JA, Xu LC, Parker N, Vetzel M, Leamon CP. Preclinical evaluation of ${ }^{99 \mathrm{~m}} \mathrm{Tc}-$ EC20 for imaging folate receptor-positive tumors. J Nucl Med. 2004;45:857-866.

14. Fisher RE, Siegel BA, Edell SL, et al. Exploratory study of ${ }^{99 \mathrm{~m} T c-E C 20}$ imaging for identifying patients with folate receptor-positive solid tumors. J Nucl Med. 2008; 49:899-906.

15. Leamon CP, Parker MA, Vlahov IR, et al. Synthesis and biological evaluation of EC20: a new folate-derived, ${ }^{99 \mathrm{~m} T c-b a s e d ~ r a d i o p h a r m a c e u t i c a l . ~ B i o c o n j u g ~ C h e m . ~}$ 2002;13:1200-1210.

16. Shimon I, Melmed S. Management of pituitary tumors. Ann Intern Med. 1998;129:472-483.

17. Leamon CP, Reddy JA. Folate-targeted chemotherapy. Adv Drug Deliv Rev. 2004;56:1127-1141.

18. Lu Y, Sega E, Leamon CP, Low PS. Folate receptor-targeted immunotherapy of cancer: mechanism and therapeutic potential. Adv Drug Deliv Rev. 2004;56:1161-1176.

19. Low PS, Antony AC. Folate receptor-targeted drugs for cancer and inflammatory diseases. Adv Drug Deliv Rev. 2004;56:1055-1058.

20. Müller C, Schubiger PA, Schibli R. Isostructural folate conjugates radiolabeled with the matched pair ${ }^{99 \mathrm{~m}} \mathrm{Tc} /{ }^{188} \mathrm{Re}$ : a potential strategy for diagnosis and therapy of folate receptor-positive tumors. Nucl Med Biol. 2007;34:595-601.

21. Ke CY, Mathias CJ, Green MA. The folate receptor as a molecular target for tumor-selective radionuclide delivery. Nucl Med Biol. 2003;30:811-817.

22. Ke CY, Mathias CJ, Green MA. Folate-receptor-targeted radionuclide imaging agents. Adv Drug Deliv Rev. 2004;56:1143-1160. 
23. Hilgenbrink AR, Low PS. Folate receptor-mediated drug targeting: from therapeutics to diagnostics. J Pharm Sci. 2005;94:2135-2146.

24. Mathias CJ, Wang S, Lee RJ, Waters DJ, Low PS, Green MA. Tumor-selective radiopharmaceutical targeting via receptor-mediated endocytosis of gallium-67deferoxamine-folate. J Nucl Med. 1996;37:1003-1008.

25. Wang S, Luo J, Lantrip DA, et al. Design and synthesis of $\left[{ }^{111} \mathrm{In}\right] \mathrm{DTPA}$-folate for use as a tumor-targeted radiopharmaceutical. Bioconjug Chem. 1997;8:673-679.

26. Mathias CJ, Wang S, Waters DJ, Turek JJ, Low PS, Green MA. Indium-111DTPA-folate as a potential folate-receptor-targeted radiopharmaceutical. J Nucl Med. 1998;39:1579-1585.

27. Guo W, Hinkle GH, Lee RJ. ${ }^{99 \mathrm{~m}}$ Tc-HYNIC-folate: a novel receptor-based targeted radiopharmaceutical for tumor imaging. J Nucl Med. 1999;40:1563-1569.

28. Ilgan S, Yang DJ, Higuchi T, et al. ${ }^{99 \mathrm{~m}}$ Tc-ethylenedicysteine-folate: a new tumor imaging agent-synthesis, labeling and evaluation in animals. Cancer Biother Radiopharm. 1998;13:427-435.

29. Mathias CJ, Hubers D, Low PS, Green MA. Synthesis of [ $\left.{ }^{99 \mathrm{~m}} \mathrm{Tc}\right] \mathrm{DTPA}$-folate and its evaluation as a folate-receptor-targeted radiopharmaceutical. Bioconjug Chem. 2000; 11:253-257.

30. Trump DP, Mathias CJ, Yang Z, Low PS, Marmion M, Green MA. Synthesis and evaluation of ${ }^{99 \mathrm{~m}} \mathrm{Tc}(\mathrm{CO})(3)$-DTPA-folate as a folate-receptor-targeted radiopharmaceutical. Nucl Med Biol. 2002;29:569-573.

31. Müller C, Schubiger PA, Schibli R. Synthesis and in vitro/in vivo evaluation of novel ${ }^{99 \mathrm{~m}} \mathrm{Tc}(\mathrm{CO}) 3$-folates. Bioconjug Chem. 2006;17:797-806.
32. Müller C, Forrer F, Schibli R, Krenning EP, de Jong M. SPECT study of folate receptor-positive malignant and normal tissues in mice using a novel ${ }^{99 \mathrm{~m}} \mathrm{Tc}-$ radiofolate. J Nucl Med. 2008;49:310-317.

33. Weitman SD, Lark RH, Coney LR, et al. Distribution of the folate receptor GP38 in normal and malignant cell lines and tissues. Cancer Res. 1992;52:3396-3401.

34. Rosenthal MS, Cullom J, Hawkins W, Moore SC, Tsui BM, Yester M. Quantitative SPECT imaging: a review and recommendations by the Focus Committee of the Society of Nuclear Medicine Computer and Instrumentation Council. J Nucl Med. 1995;36:1489-1513.

35. Rousset OG, Ma Y, Evans AC. Correction for partial volume effects in PET: principle and validation. J Nucl Med. 1998;39:904-911.

36. Du Y, Tsui BM, Frey EC. Partial volume effect compensation for quantitative brain SPECT imaging. IEEE Trans Med Imaging. 2005;24:969-976.

37. David R, Koulibaly M, Benoit M, et al. Striatal dopamine transporter levels correlate with apathy in neurodegenerative diseases: a SPECT study with partial volume effect correction. Clin Neurol Neurosurg. 2008;110:19-24.

38. Willowson K, Bailey DL, Baldock C. Quantitative SPECT reconstruction using CT-derived corrections. Phys Med Biol. 2008;53:3099-3112.

39. Low PS, Kularatne SA. Folate-targeted therapeutic and imaging agents for cancer. Curr Opin Chem Biol. 2009;13:256-262.

40. Leamon CP, Jackman AL. Exploitation of the folate receptor in the management of cancer and inflammatory disease. Vitam Horm. 2008;79:203-233. 